\title{
Survey Results on Why CS Faculty Adopt New Teaching Practices
}

\author{
Christopher Lynnly Hovey \\ University of Colorado Boulder \\ Boulder, CO USA \\ hoveyc@colorado.edu
}

\author{
Lecia Barker \\ University of Colorado Boulder \\ Boulder, CO USA \\ barkerl@colorado.edu
}

\author{
Vaughan Nagy \\ University of Colorado Boulder \\ Boulder, CO USA \\ vaughan.nagy@colorado.edu
}

\begin{abstract}
In a previous paper, we explored results from the first stage of a two-part research project designed to uncover what influences computer science (CS) faculty to adopt new teaching practices. In the first phase, we conducted interviews, classroom observations, and focus groups with faculty to better understand the organizational, individual, and social factors that influence faculty adoption. Here we discuss findings from the second phase of the project, which uses survey data from 821 CS faculty at 595 institutions in the U.S. to investigate the prevalence of themes uncovered during the qualitative phase. Results show that faculty who tried an innovation were motivated primarily by concerns for students' learning and course experience, including their engagement and participation. Also important were the "fit" with existing practices and tools, and the logistics of implementing an innovation. Factors that reduced faculty willingness to try an innovation include a lack of time, logistical issues, and satisfaction with their current teaching practices. Faculty learned about the innovations they later adopted through presentations and workshops at conferences and at their home institutions, and through conversations with respected colleagues who teach in similar contexts. Implications for encouraging more widespread usage of teaching techniques that improve diversity and student learning are discussed.
\end{abstract}

\section{KEYWORDS}

faculty adoption of teaching innovations; propagating studentcentered teaching; interactive learning dissemination; lecturing; pedagogy

\section{ACM Reference format:}

Christopher Lynnly Hovey, Lecia Barker, and Vaughan Nagy. 2019. Survey Results on Why CS Faculty Adopt New Teaching Practices. In Proceedings of the $50^{\text {th }}$ ACM Technical Symposium on Computer Science Education (SIGCSE '19), February 27-March 2, 2019, Minneapolis, MN, USA, 7 pages. https://doi.org/10.1145/3287324.3287420

Permission to make digital or hard copies of all or part of this work for personal or classroom use is granted without fee provided that copies are not made or distributed for profit or commercial advantage and that copies bear this notice and the full citation on the first page. Copyrights for components of this work owned by others than ACM must be honored. Abstracting with credit is permitted. To copy otherwise, or republish, to post on servers or to redistribute to lists, requires prior specific permission and/or a fee. Request permissions from Permissions@acm.org.

SIGCSE '19, February 27-March 2, 2019, Minneapolis, MN, USA

(c) 2019 Association for Computing Machinery.

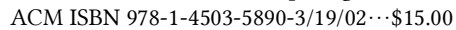

https://doi.org/10.1145/3287324.3287420

\section{INTRODUCTION}

Many computer science (CS) departments in the U.S. are experiencing a "surge" in the number of students declaring the major [5]. However, it is unclear whether or not the standard repertoire of teaching practices that are used in CS classrooms will be able to address incoming students' expectations for more interactive, dynamic instruction [4]. Innovative, evidence-based teaching stragies for CS education like Peer Instruction [17], media computation [10,19], and using meaningful, socially relevant examples and content [3] are effective ways of attracting more diverse students, of improving students' performance, engagement, and intention to continue in the major, and of addressing growing enrollments. However, recent research indicates that most CS faculty describe their teaching as encompassing both instructor- and student-centered practices $[8,9]$. Findings associated with the research we present here [13] indicate that when asked about the frequency of using various teaching practices in a specific course, most CS faculty reported presenting content by lecturing more frequently than using any of the seven student-centered instructional techniques provided in the survey. These results collectively suggest that there is a need to increase the use of evidence-based teaching practices among CS faculty in higher education. Addressing this need requires knowing more about why faculty change the way they teach, to better inform the design of intentional propagation strategies [18].

To that end, this paper reports on the second of a two-phase research project intended to increase our understanding of what influences CS faculty to try out new teaching practices. In the first phase of the project, we interviewed and conducted classroom observations with 66 CS faculty, the results of which were presented in [2] and summarized below. The analysis of our qualitative data provided us preliminary insights and rich description about faculty adoption in CS higher education, but those results do not allow us to generalize beyond those participants. In the present paper, we investigate how our qualitative findings relate to the rest of the field of CS higher education, using survey data from 821 CS faculty teaching in an estimated 595 universities, colleges, and community colleges in the United States.

\section{A SUMMARY OF QUALITATIVE RESULTS}

In [2], and to a lesser degree in [1], we described the results of a qualitative study in which we conducted theory-driven, semistructured interviews and observations with 66 faculty who 
teach CS introductory courses. Participants were selected using parameters intended to maximize the diversity of opinions and experiences, including institutional and personal criteria. Faculty, ranging from adjunct instructors to department chairs, were asked to describe their teaching and occupational contexts; their experiences with using student- and instructor-centered teaching practices; their beliefs about teaching, research, learning, and the nature of academia; and their interactions with and attitudes towards their students, peers, department administration, and the community of CS educators. Recordings were transcribed and then analyzed using both emergent and theory-based coding. More information about the research methods used in this phase is available in [1] and [2].

The remainder of this section describes principle findings from phase 1 of our project, with additional anecdotes from the qualitative data. Where applicable, we also cite studies from CS and other STEM fields as they support or contradict our findings. A more encompassing review of propagation and adoption research in CS and STEM higher education is available in [18].

\subsection{Why Faculty Try New Teaching Practices}

Mirroring theory and empirical findings in physics education research [12], and $\mathrm{Ni}$, Guzdial, and colleagues' work in CS $[7,14,15]$, we found that faculty typically try a new teaching practice or technique because they intentionally seek out solutions to a problem they have identified. The most common problems that motivated CS faculty to try new teaching practices were sub-par student learning (usually expressed as low student performance), insufficient pre-college or pre-course preparation, and low perceived student engagement (e.g., students looking bored or inattentive)-results also found in other CS studies [7,14,15]. Faculty often described responding to explicit or implicit student feedback (see [1] for more detail), especially regarding whether or not to continue using a practice; in some cases, faculty also gained awareness from students through direct and indirect suggestions via overhearing conversations, end-of-term reviews, etc. Some faculty mentioned being motivated to try a new practice because they believed that instructor-centered teaching might deter underrepresented students (women and minorities) from pursuing CS degrees, a motivation also discussed in [15].

Some faculty described hearing about a new teaching strategy or tool that they felt sounded interesting, without necessarily having a problem to address. The practice was typically described as being superior to whatever was already in use, by virtue of the advantages that it offered or simply because it offered a deviation from the status quo. In some cases, faculty were asked to try the practice by a colleague or a developer.

Some faculty reported substantial challenges, or were disincentivized to seek out or try new teaching techniques. Some junior faculty reported that they were less willing to try new teaching because they felt that experiementing with teaching could be detrimental to their tenure case, especially if the new practice would not be well-received by students. One interviewee described having difficulty in her tenuring case because she had received high performance evaluations in both research and teaching; she was treated incredulously by at least one member of her tenuring committee who did not believe someone could be good at both aspects of the job. Other faculty reported not trying or discontinuing certain practices on the pretext that it might not "go over well" with their students.

Faculty discussed other reasons for abstaining from trying a practice. Weighing the amount of time needed to learn about, prepare, and implement an innovation against the time needed for other teaching work was a common consideration among respondents. This finding is echoed in [14], which found that prep time was among the most common concerns for CS faculty (and among physics faculty [11]). Our respondents reported a willingness to put in time to investigate and try a new practice as part of the regular teaching workload, but they needed to feel secure that it would benefit students. Faculty described unfamiliarity with innovative teaching as being a barrier, contrasting their personal experiences as students that often only included passively sitting through "straight lecture" and doing independent study. Conversely, one respondent discussed trying an innovative teaching strategy that they had experienced as a student because it had excited them about computing.

Some faculty described how their department's culture, insitutional policies or context, and physical resources influenced adoption and continued use. For example, classroom layouts and available equipment often preemptively stopped faculty from trying practices they had considered. Stadium-style seating often prompted lecture-style presentations simply because the space was not conducive to interaction. In other cases, the room provided a necessary, but not sufficient, boon to the instructor's willingness to try an innovation. For example, one respondent reported that collaborative work was aided because lecture and lab were colocated in the same room.

Faculty also frequently discussed a tension between trying new teaching and "covering material"; in other words, they felt innovative teaching might increase students' depth of learning, but it would slow down the pace of the course and reduce the instructor's ability to relay a breadth of knowledge (e.g., more topics). This tension was particularly in evidence when faculty taught courses that were part of a sequence or set curriculum; faculty were afraid of frustrating or disappointing their peers if students were not adequately prepared for the next course(s) in the sequence. In rare cases, what was seen as inflexible department committee or administrative control over curriculum also influenced faculty not to try certain pedagogical techniques.

\subsection{How Faculty Hear about Practices}

Faculty reported several different communication channels through which they were exposed to an innovative practice. Most commonly, faculty found out about an innovation from informal conversations with peers, or from conference presentations at CAHSI, SIGCSE, FIE, or the NCWIT Summit. Personal discussions between colleagues about teaching or classroom issues often spurred adoption. For others, teaching new classes caused them to ask colleagues for syllabi and teaching materials; these resources required innovative teaching methods that would then be "tried out" on an experiemental basis along with the curriculum. Recommendations were typically persuasive if they came from peers with personal connections, including former mentors or graduate students, or from respected strangers with strong personal or institutional 
reputations (for teaching or research). Similarities in institutional, teaching, or research contexts-what Everett Rogers would describe as "homophily" or sameness [16]-were also persuasive elements for conference presenters. Evidence from empirical studies was not typically a consideration, and in at least one case, a faculty member dismissed evaluative studies as being inherently biased.

Faculty also mentioned learning about innovations through funded initiatives, either through grant opportunities from organizations like the National Science Foundation or through their campus's center for teaching and learning. Funding also factored heavily into faculty routinely using the innovation.

Qualitative results provide a rich description of how faculty learn of innovations and why they adopt them. Phase 2 of our project involved constructing and disseminating a survey to investigate how prevalent these, and other theory-based concerns, are among CS faculty. Below we describe our methods and results, followed by a discussion of how insights might contribute to increasing adoption of teaching practices.

\section{METHODS}

\subsection{Survey Construction and Design}

The survey was constructed using themes that emerged from transcripts of the interviews, observations, and focus groups from the first phase of the project. Survey items were crafted using the word choices and thematic considerations that faculty volunteered in interviews. This was done in an effort to reduce respondents' cognitive load and survey fatigue, and improve response validity and reliability $[6,20]$. The survey asked faculty to provide the name and enrollment of a course they had taught recently, preferably one that students take early in the curriculum, and the frequency of using certain practices. Faculty were then asked whether or not they had ever tried using a teaching practice in that course that they had not used before, and if so, what was it. Responses to this question were then used to route "yes" participants, and the name of their innovation, to various banks of questions about how they found out about the innovation, what motivated them to try it, what outcomes occurred when they tried it, whether they still used it, and why. Faculty who said that they had not tried something new were branched past these questions. Faculty were also asked to select an innovation that they had not tried from set list, and then were asked a battery of follow up questions regarding reasons for non-use (lack of info, various hypothesized inhibitors, etc.). The survey was piloted among $10 \mathrm{CS}$ faculty of various ranks at a large, public university. Their feedback was incorporated into a final survey, which was disseminated online.

\subsection{Sample Development}

To develop the sample, we used the U.S. Department of Education's Integrated Postsecondary Education Database System (IPEDS) [21] to generate a list of institutions per institutional type that awarded bachelor's or associate degrees in 2014 and 2015 in "computer science" (Classification of Instructional Program (CIP) code 11.07) or in "computer and information sciences and support services" (CIP 11). We then used department websites to acquire email contact information for between 1 and 4 faculty from each institution. Emphasis was given to identifying faculty who teach lower division introductory courses. In total, links to the incentive/survey were sent to 4,088 faculty from 1,310 institutions.

\subsection{Data Collection and Respondent Profile}

3.3.1. Data Collection. To administer the survey, potential respondents were sent personalized invitations (e.g., Dear Professor <LastName>) with a link to a survey landing page offering an incentive. Faculty could voluntarily provide a contact email to receive a $\$ 20$ Amazon.com gift card. Methodology studies have shown that using pre-survey incentives and personal salutations are more likely to entice respondents who otherwise would have abstained from the survey, which increases the sample size [6]. This data set was stored separately from the actual survey, so there was no way to match email addresses with survey responses. Respondents also had the option of skipping the incentive and proceeding to the survey. The "submit" button for the incentive screen forwarded participants to one of eight survey "collector groups," which retained their institutional type without storing any personal information.

3.3.2. Sample Size. Responses were collected from the beginning of May until the end of July 2017. In total, 849 faculty accessed the link to the incentive landing page; 751 claimed the incentive, and 821 faculty continued to and completed at least the first page of the survey, resulting in a response rate of $20 \%$. Confidentiality settings prevent us from knowing the exact number, but a conservative estimate calculated from incentiveto-survey transfers by institutional type suggests that at least 595 institutions are represented in the data.

3.3.3. Respondent Profile. Table 1 shows the distribution of respondents by institutional type, which intentionally approximates the proportions of institutions for each type found in IPEDS to strengthen the representativeness of the data. The timing and frequency of reminders for participation were sent to specific groups based on the evolving distribution of the sample.

How long faculty had been teaching was normally distributed across three intervals: "up to 5 years" (25\%), "between 6 and 20 years" (49\%), and "more than 20 years" (26\%). Faculty were well distributed across ranks: adjuncts and instructor $(20 \%)$, assistant professor (25\%), associate professor $(25 \%)$, and full professor $(27 \%)$-with an additional 3\% reporting being either a chair or dean, or having no rank system. Rank strongly correlated with tenure status categories: non-tenure track (21\%), tenure-track (25\%), and tenured (55\%). Women comprised $22 \%$ of the sample, and an additional $8 \%$ of the sample described their

Table 1: Respondents by Institutional Types

\begin{tabular}{lrr}
\hline Institutional Type & $\mathbf{N}$ & Percent \\
\hline Two-Year Associate-Granting & 164 & $20.0 \%$ \\
Research Intensive/Extensive & 133 & $16.2 \%$ \\
Historically Black College/University & 26 & $3.2 \%$ \\
Hispanic Serving Institution & 101 & $12.3 \%$ \\
Tribal College & 5 & $0.6 \%$ \\
Small (enrollment $=1-4,999)$ & 209 & $25.5 \%$ \\
Medium (enrollment $=5,000-9,999)$ & 47 & $5.7 \%$ \\
Large (enrollment $=10,000+)$ & 136 & $16.6 \%$ \\
\hline Total & $\mathbf{8 2 1}$ & $\mathbf{1 0 0 \%}$ \\
\hline
\end{tabular}


gender identity as "not listed," "prefer not to respond," or opted to leave the question blank. Of the 646 respondents who provided their race/ethnicity via an open-ended question, $81 \%$ were White, $12 \%$ were Asian, and $8 \%$ were Black, Hispanic, Native/Indian, or other. We were unable to find data on the demographic features of the full population of CS faculty with which we could compare our sample.

\section{RESULTS}

In total, $72.4 \%(\mathrm{n}=584)$ of faculty responded that they had tried a new teaching practice. These respondents were then asked questions about how they learned of the practice and what influenced them to try it. Values displayed in the following tables reflect the percentage $(\%)$ and number $(\mathrm{N})$ of respondents who selected each response option. "Don't know/not applicable," auto-skipped, and non-response answers are excluded. Items are ordered by descending levels of overall agreement.

\subsection{Why Faculty Try New Teaching}

4.1.1. Reasons for Trying. Faculty were asked two banks of questions regarding their considerations and motivations for trying a new practice. Results are displayed in Table 2. Four of the top five considerations center on intended positive outcomes for students regarding the course, i.e., their understanding, engagement, performance, and participation. "Fit" with existing practices and tools was also important to a majority of faculty. The next three items represent logistical considerations, including the knowledge and time required to try the innovation. Concerns over how much time it would take to try, and potential interference with covering material, were less important than interviews led us to expect, although over $50 \%$ of respondents agreed to each item. Less than half of respondents felt their decision was motivated or influenced by an interest in students' social skills development, covering more material, saving time, or satisfying a request to try it from either students or colleagues. One-fourth of respondents received help from a learning center.

4.1.2. Reasons for Not Trying (Yet). Respondents were also asked to select an innovative teaching practice that they "had heard of but had not (yet) tried" from a set list. They were then asked to report their level of agreement or disagreement with statements about why they had not tried it. Specific responses and percentage frequencies are reported in Table 3. Results indicate that not having time to try the practice is the strongest and most common inhibiter of faculty adoption. Satisfaction with current teaching practices was also very common. Not having access to the necessary resources, and not being familiar with the practice-essentially logistical concerns-were also somewhat common reasons why faculty abstained from using a practice.

Less than half of the sample expressed concerns about how students would respond to using the innovation (akin to "fit" with how students learn), or that the practice might interfere with covering material. Given their importance for adoption (see Table 1), these two considerations appear to be "heat" factors for
Table 2: Motivations and Considerations for Adoption

\begin{tabular}{|c|c|c|c|c|c|}
\hline Motivation* or Consideration & \multicolumn{2}{|r|}{ Strg } & Dis. & Agr. & $\begin{array}{l}\text { Strg } \\
\text { Agr. }\end{array}$ \\
\hline I wanted to improve my students' & $\%$ & $0 \%$ & $1 \%$ & $28 \%$ & $70 \%$ \\
\hline understanding of course content ${ }^{*}$ & $\mathrm{~N}$ & 1 & 7 & 159 & 392 \\
\hline \multirow{2}{*}{$\begin{array}{l}\text { I wanted to increase my students' } \\
\text { engagement or interest* }\end{array}$} & $\%$ & $0 \%$ & $2 \%$ & $31 \%$ & $66 \%$ \\
\hline & $\mathrm{N}$ & 2 & 13 & 173 & 372 \\
\hline \multirow{2}{*}{$\begin{array}{l}\text { I wanted to improve my students' } \\
\text { performance in the class* }\end{array}$} & $\%$ & $0 \%$ & $4 \%$ & $34 \%$ & $62 \%$ \\
\hline & $\mathrm{N}$ & 1 & 20 & 189 & 348 \\
\hline \multirow{2}{*}{$\begin{array}{l}\text { I believed it would be a better "fit" } \\
\text { with how my students learn }\end{array}$} & $\%$ & $0 \%$ & $5 \%$ & $51 \%$ & $43 \%$ \\
\hline & $\mathrm{N}$ & 1 & 29 & 275 & 232 \\
\hline \multirow{2}{*}{$\begin{array}{l}\text { I wanted to increase my students' } \\
\text { participation in class* }\end{array}$} & $\%$ & $1 \%$ & $6 \%$ & $27 \%$ & $65 \%$ \\
\hline & $\mathrm{N}$ & 7 & 36 & 150 & 363 \\
\hline \multirow{4}{*}{$\begin{array}{l}\text { I felt I had enough resources (e.g., } \\
\text { funding, hardware, etc.) to try it } \\
\text { I had clear expectations for what I } \\
\text { thought it would do }\end{array}$} & $\%$ & $2 \%$ & $8 \%$ & $52 \%$ & $38 \%$ \\
\hline & $\mathrm{N}$ & 9 & 42 & 274 & 198 \\
\hline & $\%$ & $1 \%$ & $12 \%$ & $60 \%$ & $27 \%$ \\
\hline & $\mathrm{N}$ & 3 & 67 & 334 & 151 \\
\hline \multirow{2}{*}{$\begin{array}{l}\text { I understood the necessary } \\
\text { logistics (time, resources, etc.) } \\
\text { before trying it }\end{array}$} & $\%$ & $1 \%$ & $18 \%$ & $53 \%$ & $28 \%$ \\
\hline & $\mathrm{N}$ & 7 & 100 & 292 & 154 \\
\hline \multirow{2}{*}{$\begin{array}{l}\text { I wanted to better prepare } \\
\text { students for their careers* }\end{array}$} & $\%$ & $11 \%$ & $11 \%$ & 39 & $40 \%$ \\
\hline & $\mathrm{N}$ & 56 & 58 & 206 & 3 \\
\hline \multirow{2}{*}{$\begin{array}{l}\text { It was recommended by someone I } \\
\text { trust }\end{array}$} & $\%$ & $12 \%$ & $13 \%$ & $45 \%$ & $30 \%$ \\
\hline & $\mathrm{N}$ & 50 & 55 & 190 & 128 \\
\hline \multirow{2}{*}{$\begin{array}{l}\text { I wanted to be more inclusive of } \\
\text { underrepresented students* }\end{array}$} & $\%$ & $19 \%$ & $22 \%$ & $37 \%$ & $22 \%$ \\
\hline & $\mathrm{N}$ & 91 & & & \\
\hline \multirow{2}{*}{$\begin{array}{l}\text { I thought I would be able to use it } \\
\text { in all of the courses I teach }\end{array}$} & $\%$ & $10 \%$ & $33 \%$ & $37 \%$ & \\
\hline & $\mathrm{N}$ & 53 & 179 & 201 & 113 \\
\hline \multirow{2}{*}{$\begin{array}{l}\text { I was concerned that it would take } \\
\text { a lot of time to implement }\end{array}$} & $\%$ & $11 \%$ & $41 \%$ & $37 \%$ & $12 \%$ \\
\hline & $\mathrm{N}$ & 59 & 223 & 202 & 65 \\
\hline \multirow{4}{*}{$\begin{array}{l}\text { I was concerned that I would not } \\
\text { be able to cover as much material } \\
\text { I wanted students to improve their } \\
\text { social skills* }\end{array}$} & $\%$ & $19 \%$ & $42 \%$ & $31 \%$ & $8 \%$ \\
\hline & $\mathrm{N}$ & 10 & & & 43 \\
\hline & $\%$ & $30 \%$ & $31 \%$ & $28 \%$ & $11 \%$ \\
\hline & $\mathrm{N}$ & 146 & 152 & 137 & 55 \\
\hline \multirow{2}{*}{ I wanted to cover more material ${ }^{*}$} & $\%$ & $30 \%$ & $44 \%$ & $17 \%$ & $9 \%$ \\
\hline & $\mathrm{N}$ & 159 & 236 & 91 & 48 \\
\hline \multirow{2}{*}{$\begin{array}{l}\text { I received help from my } \\
\text { institution's center for teaching }\end{array}$} & $\%$ & $42 \%$ & $32 \%$ & $16 \%$ & $9 \%$ \\
\hline & $\mathrm{N}$ & 20 & & 78 & 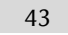 \\
\hline \multirow{2}{*}{ I wanted to save time* } & $\%$ & $39 \%$ & $40 \%$ & $13 \%$ & $7 \%$ \\
\hline & $\mathrm{N}$ & 211 & 213 & 72 & 39 \\
\hline \multirow{2}{*}{$\begin{array}{l}\text { A colleague asked me to } \\
\text { try it * }\end{array}$} & $\%$ & $46 \%$ & $39 \%$ & $10 \%$ & $4 \%$ \\
\hline & $\mathrm{N}$ & 221 & 187 & 49 & 20 \\
\hline \multirow{4}{*}{$\begin{array}{l}\text { My students suggested that I } \\
\text { try it* } \\
\text { My department required me to } \\
\text { try it* }\end{array}$} & $\%$ & $59 \%$ & $33 \%$ & $6 \%$ & $2 \%$ \\
\hline & $\mathrm{N}$ & 301 & 166 & 30 & 10 \\
\hline & $\%$ & $71 \%$ & $27 \%$ & $1 \%$ & $2 \%$ \\
\hline & $\mathrm{N}$ & 360 & 136 & 6 & 8 \\
\hline \multicolumn{6}{|c|}{$\begin{array}{l}\text { Notes: Strg Dis. = Strongly Disagree; Dis. = Disagree; Agr. = Agree; Strg Agr. = } \\
\text { Strongly Agree, and N = Number of respondents. Items are listed in descending } \\
\text { order by percentage of total agreement (i.e., Agree + Strongly Agree). } \\
\text { Items without asterisks were prompted in the survey as, "Please reflect on your } \\
\text { thoughts about the teaching practice '<piped text'> when you were first deciding } \\
\text { if you would try it. To what extent do you agree or disagree with the following } \\
\text { considerations?" Asterisks indicate the survey prompt asked, "To what extent do } \\
\text { you agree or disagree that the following considerations motivated your decision } \\
\text { to try the teaching practice '<piped text>'?" }\end{array}$} \\
\hline
\end{tabular}

motivating adoption, but their absences are not necessarily "chilling" factors for adoption, metaphorically speaking.

Similar proportions of faculty, about $15 \%$ to $20 \%$, had issues with classroom physical setups or with class enrollments. Tenure considerations, as well as direct discouragement from peers or departmental regulations were very uncommon, receiving less than $10 \%$ agreement each. 
Table 3: Reasons for Not (Yet) Trying an Innovation

\begin{tabular}{|c|c|c|c|c|c|}
\hline $\begin{array}{l}\text { Reason for Not (Yet) Having } \\
\text { Tried an Innovation }\end{array}$ & \multicolumn{2}{|r|}{ Strg } & Dis. & Agr. & $\begin{array}{l}\text { Strg } \\
\text { Agr. }\end{array}$ \\
\hline I have not had enough time to try & $\%$ & $5 \%$ & $17 \%$ & $46 \%$ & $32 \%$ \\
\hline it & $\mathrm{N}$ & 29 & 103 & 275 & 190 \\
\hline I am satisfied with how I teach & $\%$ & $2 \%$ & $27 \%$ & $54 \%$ & $16 \%$ \\
\hline now & $\mathrm{N}$ & 15 & 172 & 341 & 103 \\
\hline \multirow{2}{*}{$\begin{array}{l}\text { I have not had access to the } \\
\text { resources needed to try it }\end{array}$} & $\%$ & $7 \%$ & $35 \%$ & $38 \%$ & $20 \%$ \\
\hline & $\mathrm{N}$ & 41 & 196 & 217 & 113 \\
\hline I am not familiar with the & $\%$ & $11 \%$ & $35 \%$ & $38 \%$ & $16 \%$ \\
\hline logistics/resources needed & $\mathrm{N}$ & 71 & 224 & 243 & 100 \\
\hline \multirow{2}{*}{$\begin{array}{l}\text { It might not work for the type of } \\
\text { students I teach }\end{array}$} & $\%$ & $13 \%$ & $43 \%$ & $36 \%$ & $8 \%$ \\
\hline & $\mathrm{N}$ & 70 & 226 & 190 & 43 \\
\hline \multirow{2}{*}{$\begin{array}{l}\text { There is not enough evidence that } \\
\text { it works }\end{array}$} & $\%$ & $9 \%$ & $50 \%$ & $33 \%$ & $8 \%$ \\
\hline & $\mathrm{N}$ & 41 & 221 & 145 & 33 \\
\hline \multirow{2}{*}{ My students might not like it } & $\%$ & $10 \%$ & $51 \%$ & $33 \%$ & $6 \%$ \\
\hline & $\mathrm{N}$ & 47 & 250 & 161 & 31 \\
\hline \multirow{2}{*}{$\begin{array}{l}\text { It might negatively impact my } \\
\text { ability to cover material }\end{array}$} & $\%$ & $13 \%$ & $48 \%$ & $30 \%$ & $9 \%$ \\
\hline & $\mathrm{N}$ & 72 & 262 & 162 & 50 \\
\hline \multirow{2}{*}{$\begin{array}{l}\text { My classroom's physical setup } \\
\text { prevents me from trying it }\end{array}$} & $\%$ & $20 \%$ & $59 \%$ & $16 \%$ & $5 \%$ \\
\hline & $\mathrm{N}$ & 109 & 316 & 86 & 27 \\
\hline \multirow{2}{*}{$\begin{array}{l}\text { My class enrollment is too large to } \\
\text { use it in my class(es) }\end{array}$} & $\%$ & $24 \%$ & $58 \%$ & $12 \%$ & $6 \%$ \\
\hline & $\mathrm{N}$ & 132 & 311 & 64 & 33 \\
\hline \multirow{2}{*}{$\begin{array}{l}\text { My class enrollment is too small to } \\
\text { use it in my class(es) }\end{array}$} & $\%$ & $27 \%$ & $59 \%$ & $12 \%$ & $3 \%$ \\
\hline & $\mathrm{N}$ & 141 & 307 & 62 & 14 \\
\hline \multirow{2}{*}{$\begin{array}{l}\text { It might interfere with getting } \\
\text { tenure or promotion }\end{array}$} & $\%$ & $50 \%$ & $41 \%$ & $6 \%$ & $3 \%$ \\
\hline & $\mathrm{N}$ & 269 & 219 & 33 & 17 \\
\hline \multirow{2}{*}{$\begin{array}{l}\text { A colleague or peer has } \\
\text { discouraged me from trying it }\end{array}$} & $\%$ & $41 \%$ & $53 \%$ & $5 \%$ & $2 \%$ \\
\hline & $\mathrm{N}$ & 228 & 293 & 28 & 9 \\
\hline \multirow{2}{*}{$\begin{array}{l}\text { It would not be possible to try it } \\
\text { because of how my department } \\
\text { sets curriculum }\end{array}$} & $\%$ & $45 \%$ & $49 \%$ & $5 \%$ & $1 \%$ \\
\hline & $\mathrm{N}$ & 249 & 274 & 29 & 7 \\
\hline
\end{tabular}

Notes: Strg Dis. = Strongly Disagree; Dis. = Disagree; Agr. = Agree; Strg Agr. = Strongly Agree, and $\mathrm{N}=$ Number of respondents. Items are listed in descending order by percentage of total agreement (i.e., Agree + Strongly Agree).

Survey prompt: "To what extent do you agree or disagree that the following influenced you to not try '<piped text>'?"

\subsection{How Faculty Learn About Innovations}

Faculty were asked to describe both the source of information and the context in which they learned about their innovations. Response options included people and settings derived from interviews, as well as open-ended options where faculty could describe each in their own words. Because of the interdependence and complexity of sources and contexts, we realized that these two survey items would need to be manually cross tabulated into a single variable. The results of this reorganization are presented in Table 4, listed in descending order of prevalence. Because we were not able to ask follow-up questions or seek clarification about the awareness situation, these results should be interpreted as preliminary indications.

Table 4: Awareness Situations

\begin{tabular}{lrr}
\hline Institutional Type & N & Percent \\
\hline Conversation with another faculty member & 161 & $38.5 \%$ \\
Presentation/workshop at a conference & 90 & $21.5 \%$ \\
Presentation/workshop at my institution & 74 & $17.7 \%$ \\
Research, media, or publication & 68 & $16.3 \%$ \\
From a student (grad or undergrad) & 9 & $2.2 \%$ \\
Experience while being a student & 7 & $1.7 \%$ \\
Sales pitch & 5 & $1.2 \%$ \\
Email from center for teaching and learning & 4 & $1.0 \%$ \\
\hline TOTAL & $\mathbf{4 1 8}$ & $\mathbf{1 0 0 \%}$ \\
\hline
\end{tabular}

The two most common situations in which faculty learned of an innovation they later adopted were through conference presentations and workshops (either at conferences or the home institution), and through informal conversations with colleagues. Collectively, these made up approximately three-fourths of all awareness situations. Somewhat in contrast to our qualitative data, approximately one-tenth of situations involved personally directed research, popular media like prominent CS educators' blog posts, and academic publications. This finding suggested that the degree to which formal evidence diffuses among CS faculty may hinge on endorsement and active promotion of mavens-highly visible, well-respected, notable persons with strong reputations in the CS education community.

Students explicitly asking faculty to change how they teach was not common. Nine respondents described hearing the recommendation from either a graduate or undergraduate student, corroborating evidence from Table 2 in which only eight respondents agreed to some level that student recommendations had been a consideration in their decision to adopt. We caution that this result does not negate the importance students have in encouraging or discouraging continued usage [1,2]. Similarly, personal experience as a student, being approached by a sales representative, and emails from centers for teaching and learning were relatively uncommon avenues through which faculty discovered new teaching practices.

In the qualitative data, we found that reputation and contextual similarities were important mediators in the persuasiveness of people who encouraged adoption. Therefore, respondents who reported that the awareness source was another faculty member (or who responded "other" and reported that the person was working in higher education) were asked a bank of questions related to personal and institutional reputations, and contextual similarities of the person from whom they learned about their new teaching practice. Response options and results, ranked in order of total agreement, are reported in Table 5.

The teaching reputation of the individual, and of her or his institution, were highly ranked by almost all respondents. Institutional similarity and teaching the same type of students (i.e., institutional homophily) also received a high level of overall agreement. Conversely, research and industry reputations received much less agreement. Therefore, we can conclude that the persuasiveness of a champion or propagator is strongly associated with teaching reputation, of both the individual and the institution in which they work.

\section{DISCUSSION AND IMPLICATIONS}

Many of the hypotheses generated by the qualitative phase of our project were supported in the quantitative phase. Faculty adoption is often strongly motivated by concerns for student learning and students' experience of a course, including their engagement and participation. As hypothesized by Rogers [16], a practice must "fit" with (or be compatible with) existing practices, although we found only limited evidence that concerns about "fit" were related to not trying an innovation. We also found strong evidence that the logistics of implementing an innovation, meaning the requisite knowledge, time, and 
Table 5: Source Reputation and Similarities

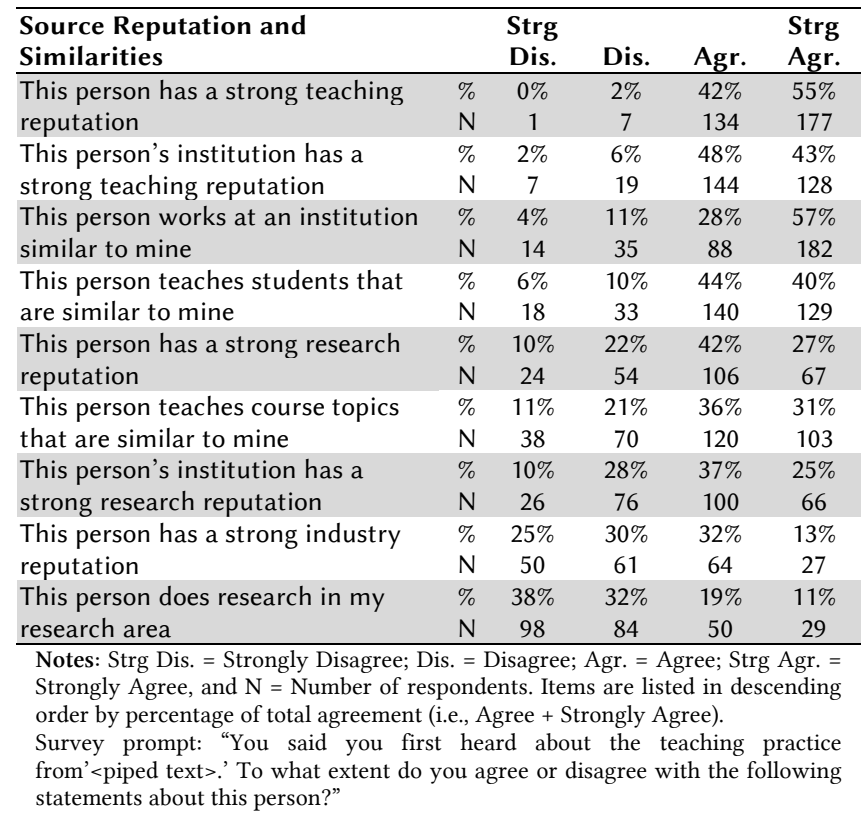

resources, also factored into faculty's trial of an innovation, and conversely, the absence of these inhibited trying a new practice.

The most prevalent awareness situation involved learning from colleagues through conversations and through conference presentations; a strong personal or institutional reputation for teaching plays a factor in eliciting new users to try an innovation.

There were a few surprises regarding the relationship between the qualitative and quantitative results. Tenure considerations were not as prevalent as expected. We found no statistical differences among faculty of different tenure statuses. Also, in the qualitative phase, we found evidence that some faculty disregard empirical studies. Survey results suggest that faculty do in fact seek out highly reputed blogs, popular media, and academic publications for teaching strategies on their own.

Although holding workshops and actively supporting faculty in learning new approaches to teaching are likely to result in long-term use, the resources for getting the word out and funding such efforts are minimal. Thus, we hope to continue this work by mining the findings for improving communication and messaging to increase the likelihood that faculty will find out about, experiment with, and routinely use effective teaching practices. As is suggested by the percent of faculty who discovered a practice in a research publication or similar medium (16\%), raising awareness of the innovation requires more than publishing results, regardless of how important evaluations are to the integrity of evidence-based practices. Many CS faculty members do not access the CS teaching literature. Personal accounts shared at conferences and through personal conversations in departments may be more persuasive than research reports. Finding "mavens" who communicate across boundaries may be a useful approach. An important way to disseminate new teaching strategies is to have faculty from a variety of contexts and environments that have successfully implemented the innovation share their experiences with their colleagues. Faculty are more likely to adopt an innovation, even if they have reservations, when the idea is promoted by someone they hold in esteem, or whom they believe is similar to them and has similar circumstances. Developers and advocates might circumvent biases by demonstrating understanding of faculty concerns and shared values, and by communicating these to faculty. They may also identify the sources most trusted by particular target audiences. Conference presenters and advocates should elucidate the "how-to" of the innovation and include honest experiences about what motivated the innovation, what worked well, how much time it took, what was challenging, and what can be improved.

Developers and advocates should seek to understand the constraints and circumstances of specific adoption audiences, especially time, funding, tenure and promotion policies, curricular sequencing and rigidity, physical space, student and departmental culture, and personal concerns. In particular, grants and other funding opportunities can allow faculty the release time, infrastructure, and curriculum vitae boost that may encourage them to innovate their teaching. By understanding these tensions, developers and advocates may be more successful at diffusing better education practices throughout CS higher education to promote retention and learning.

\section{LIMITATIONS}

As in all research, there are several limitations to this study. Despite incorporating best practices into our research methods, it is possible that our respondents are not reflective of all CS faculty. Invitations emailed to faculty described the study as, "a 15-minute survey on how faculty find out about, try out, and decide to routinely use teaching practices in their [CS] classes.” This would likely deter faculty who are disinterested in teaching. And while the survey was disseminated over several months in the summer in order to decrease the risk of competing responsibilities, some educators may not have checked their email during the recess or had time to fill out the survey. Respondents may have interpreted question prompts or response options in ways that differed from our intent, as they did for our questions about the awareness situation. Nonetheless, this study hopefully gives developers and propagators useful information about why faculty change the way they teach, which can be leveraged in developing propagation plans to encourage more widespread use of effective teaching strategies.

\section{ACKNOWLEDGEMENTS}

Thank you to the survey respondents who participated in this study, especially those that identified a scripting error that helped us fix the survey. Thank you to our colleagues Erin Arneson, Brittany Kos, Shauna Montoya, and Hannah Weber, whose help with the survey design, data wrangling, and analysis were instrumental. Thanks to Margaret Luebs, Sandra Hovey, and our SIGCSE reviewers for providing excellent substantive feedback and proof editing suggestions. Finally, thank you to the National Science Foundation for funding this study under award DUE\#1123332. 


\section{REFERENCES}

[1] Lecia Barker and Jane Gruning. 2014. The Student Prompt: Student Feedback and Change in Teaching Practices in Postsecondary Computer Science. In Proceedings of the 44th Annual Frontiers in Education Conference, 1-8. DOI:https://doi.org/10.1109/FIE.2014.7044464

[2] Lecia Barker, Christopher Lynnly Hovey, and Jane Gruning. 2015. What Influences CS Faculty to Adopt Teaching Practices? In Proceedings of the 46th ACM Technical Symposium on Computer Science Education (SIGCSE '15), 604-609. DOI:https://doi.org/10.1145/2676723.2677282

[3] Lecia Barker, Christopher Lynnly Hovey, and Leisa D. Thompson. 2014. Results of a large-scale, multi-institutional study of undergraduate retention in computing. In Proceedings of the 44th Annual Frontiers in Education Conference (FIE '14), 1693-1700. DOI:https://doi.org/10.1109/FIE.2014.7044267

[4] David Buckingham. 2007. Beyond Technology: Children's Learning in the Age of Digital Culture. Polity, Cambridge, MA.

[5] Computing Research Association. 2017. Generation CS: Computer Science Undergraduate Enrollments Surge Since 2006. Retrieved March 20, 2017 from http://cra.org/data/generation-cs/

[6] Don A. Dillman, Jolene D. Smyth, and Leah Melani Christian. 2014. Internet, phone, mail, and mixed-mode surveys: the tailored design method (Fourth edition ed.). Wiley, Hoboken, New Jersey.

[7] Davide Fossati and Mark Guzdial. 2011. The Use of Evidence in the Change Making Process of Computer Science Educators. In Proceedings of the 42Nd ACM Technical Symposium on Computer Science Education (SIGCSE '11), 685-690. DOI:https://doi.org/10.1145/1953163.1953352

[8] Scott Grissom, Sue Fitzgerald, Renée McCauley, and Laurie Murphy. 2017. Exposed! CS Faculty Caught Lecturing in Public: A Survey of Instructiona Practices. In Proceedings of the 2017 ACM SIGCSE Technical Symposium on Computer Science Education (SIGCSE '17), 261-266. DOI:https://doi.org/10.1145/3017680.3017702

[9] Scott Grissom, Renée Mccauley, and Laurie Murphy. 2017. How Student Centered is the Computer Science Classroom? A Survey of College Faculty. ACM Trans Comput Educ 18, 1 (November 2017), 5:1-5:27. DOI:https://doi.org/10.1145/3143200

[10] Mark Guzdial and Allison Elliott Tew. 2006. Imagineering Inauthentic Legitimate Peripheral Participation: An Instructional Design Approach for Motivating Computing Education. In Proceedings of the Second International Workshop on Computing Education Research (ICER '06), 51-58. DOI:https://doi.org/10.1145/1151588.1151597

[11] Charles Henderson and Melissa H. Dancy. 2007. Barriers to the use of research-based instructional strategies: The influence of both individual and situational characteristics. Phys. Rev. Spec. Top. - Phys. Educ. Res. 3, 2 (September 2007) 020102 DOI:https://doi.org/10.1103/PhysRevSTPER.3.020102

[12] Charles Henderson and Melissa H. Dancy. 2008. Physics faculty an educational researchers: Divergent expectations as barriers to the diffusion of innovations. Am. F. Phys. 76, 1 (January 2008), 79-91. DOI:https://doi.org/10.1119/1.2800352

[13] Christopher Lynnly Hovey, Lecia Barker, and Margaret Luebs. forthcoming. Frequency of Instructor- and Student-Centered Teaching Practices in Introductory CS Courses. In Proceedings of the 50th ACM Technical Symposium on Computer Science Education (SIGCSE '19). DOI:https://doi.org/10.1145/3287324.3287363

[14] Lijun Ni. 2009. What Makes CS Teachers Change?: Factors Influencing CS Teachers' Adoption of Curriculum Innovations. In Proceedings of the 40th ACM Technical Symposium on Computer Science Education (SIGCSE '09), 544-548. DOI:https://doi.org/10.1145/1508865.1509051

[15] Lijun Ni, Tom McKlin, and Mark Guzdial. 2010. How Do Computing Faculty Adopt Curriculum Innovations?: The Story from Instructors. In Proceedings of the 41st ACM Technical Symposium on Computer Science Education (SIGCSE '10), 544-548.

DOI:https://doi.org/10.1145/1734263.1734444

[16] Everett M Rogers. 2003. Diffusion of innovations. Free Press, New York

[17] Beth Simon, Sarah Esper, Leo Porter, and Quintin Cutts. 2013. Student Experience in a Student-centered Peer Instruction Classroom. In Proceedings of the Ninth Annual International ACM Conference on International Computing Education Research (ICER '13), 129-136. DOI:https://doi.org/10.1145/2493394.2493407

[18] Cynthia Taylor, Jaime Spacco, David P. Bunde, Zack Butler, Heather Bort, Christopher Lynnly Hovey, Francesco Maiorana, and Thomas Zeume. forthcoming. Propagating the Adoption of CS Educational Innovations. In Proceedings of the 23rd Annual ACM Conference on Innovation and Technology in Computer Science Education (ITiCSE Companion '18) DOI:https://doi.org/10.1145/3293881.3295785

[19] Allison Elliott Tew, Charles Fowler, and Mark Guzdial. 2005. Tracking an Innovation in Introductory CS Education from a Research University to a Two-year College. In Proceedings of the 36th SIGCSE Technical Symposium on Computer Science Education (SIGCSE '05), 416-420. DOI:https://doi.org/10.1145/1047344.1047481

[20] Roger Tourangeau. 2000. The psychology of survey response. Cambridge University Press, Cambridge; New York.

[21] U.S. Department of Education. 2016. Integrated Postsecondary Education Data System. Retrieved from https://nces.ed.gov/ipeds/ 